\title{
Effects of Task Complexity and Types of Negotiation on Language-related Episodes in ESL Classrooms
}

\author{
Lilliati Ismail, Arshad Abd. Samad \\ Faculty of Educational Studies \\ Universiti Putra Malaysia
}

\begin{abstract}
While the use of pedagogical tasks to encourage learner-learner interaction has gained recognition in promoting interlanguage development, the ways in which language forms are dealt with during these interactions remain underexplored. This study addressed the noticing of gaps in language use while dealing with tasks which are reflected by the negotiation of meaning and negotiation of form that occurred. Employing classroom-based research, this study investigated the effects of task reasoning demand and type of negotiation on frequency of language-related episodes (LREs). The grammatical items that learners focused on during their interactions were also identified and tabulated. A repeated-measures design was adopted. The participants were 76 pre-university students randomly assigned into four groups. Data were analysed using descriptive statistics and repeatedmeasures ANOVA. Results indicate that there was a significantly higher number of LREs with negotiation of meaning as opposed to negotiation of form in the task with the high reasoning demand as opposed to the task with the low reasoning demand. The current research also shows that certain grammatical features were problematic for learners across both tasks. The results have implications on the utilization of tasks for L2 learning to optimize focus on meaning and form in learner-learner interaction.
\end{abstract}

\section{Introduction}

There has been increasing interest in the role of noticing of gaps in language use while dealing with pedagogical tasks in promoting interlanguage development. The use of tasks provides the platform for interaction and there appears to be a link between 'noticing' and language learning as 'noticing' could lead to breaks in the flow of interaction during which learners would engage in negotiation of meaning or negotiation of form. Following [12] and [5], negotiation of meaning is operationalized as confirmation checks, clarification requests, and comprehension checks. Confirmation checks are any expressions 'immediately following an utterance which are designed to elicit confirmation that the utterance has been correctly heard or understood by the speaker' ([12], p. 137), comprehension checks try to 'anticipate and prevent a breakdown in communication' ([12], p.136), and clarification requests are any expression '... designed to elicit clarification of the interlocutor's preceding utterance(s)' ([12], p. 137). The outcomes of these negotiations could lead to interlanguage development. Skehan's Information Processing Model [22] and Schmidt's Noticing Hypothesis [21] underpin the roles of input and noticing. [21] proposes that noticing and paying attention to language forms could facilitate acquisition and learners need to be aware of language forms and use. [22] contends that task demand on processing resources and learner internal factors could influence noticing. Thus, the use of tasks of different reasoning demands could affect amount of noticing that would lead to negotiation of meaning and negotiation of form.

Robinson's Cognition Hypothesis [17], [18], [19] and Skehan's Trade-off Hypothesis [22], [23] rationalise the manipulation of task complexity levels to elicit negotiation of meaning and negotiation of form, thus creating learning opportunities. Negotiation and meaning and negotiation of form could have effects on the frequency of language-related episodes (LREs) that occur. LREs are defined as learners' attempts to address problematic features of the target language during classroom interaction [8]. Categories of LREs would include meaning-based, grammatical, orthographic, discourse, and lexis features [8].

[22] posited that humans have limited cognitive processing capacity. Thus, when there is a competition for attention from task content and task performance, the mind will have to prioritise one over the other. [22] argued that the cognitively demanding task would result in greater attention being given to meaning, resulting in little attention given to language forms. This trade-off in attentional capacity is one of the key arguments in the limited attentional capacity model [22], [24]. In contrast, Robinson [17], [18], [19] in his Cognition Hypothesis for task complexity contends that humans possess multiple pools of attention that are not in competition with each other. He argues that 
humans can attend to task content, task performance and language forms without one taking priority over the other. Robinson's assertions about task complexity and their effects on task performance are encompassed in the Triadic Componential Framework for task design. This framework puts forth three dimensions in a task which are task difficulty, task condition and task complexity. Task difficulty relates to learner differences such as aptitude and affective factors that affect task performance and individual perceptions of task demands. Task condition refers to participant variables such as learner background and proficiency levels, and participation factors such as one-way or two-way interaction. This current study focuses on the task complexity dimension of the framework. Task complexity refers to the inherent information processing demands of a task including attentional memory and reasoning demands.

Robinson further distinguishes task complexity into resource-directing and resource-dispersing dimensions. He uses the symbol + and - to indicate a presence $(+)$ or absence $(-)$ of an element, or a relatively greater amount $(+)$ or lesser amount $(-)$ of presence. Resource-directing variables are variables that would impose cognitive demands on the learners (+/- here and now, +/- few elements, and +/reasoning), while resource-dispersing variables would impose performative or procedural demands on the learners (+/- planning time, +/- prior knowledge and $+/$ - single task). Robinson predicts that increasing the cognitive demands along the resource-directing dimension will result in the production of more accurate and linguistically complex language with more negotiation of meaning, and increased attention to linguistic forms as learners attempt to meet the cognitive and communicative demands of the task.

Task complexity has been found to be an important factor affecting task performance and language ability. The next section will discuss recent studies that manipulated task complexity variables in the resource-directing dimension and the effects on L2 learning opportunities and L2 development.

\section{LREs and L2 learning}

The relationship between LREs and L2 development have been investigated in various contexts, with L2 development operationalised as the learning of pre-determined or any linguistic items that were discussed during the LREs. Variables investigated in these studies include learner proficiency levels, task types, and task conditions. The impact of these variables on learner-learner interaction and L2 development were measured using tests, and analysis of learner-learner interaction.
Most of these studies were conducted in controlled classroom settings using a single task or several tasks. For example, [2] investigated the effectiveness of learner-learner interaction in the learning of three grammatical items: locative prepositions, past-tense and question forms. Twentyfive ESL learners participated in three collaborative tasks. Each task was designed to elicit the use of the three target structures. Tailor-made tests were then used to assess the amount of learning that occurred as a result feedback during learner-learner interaction. Results indicated that $59 \%$ of the items tested during the tailor-made tests were answered correctly.

[26] in a study involving twenty-two L2 learners, investigated the learners' level of engagement, as operationalised by the number of turns in an LRE, and its effects on L2 learning. [26] posited that a more elaborate LRE could indicate a higher level of engagement and attention to language use. Results of the study indicated that elaborate engagement was more beneficial than limited engagement as reflected by the learners' performance on a set of questions based on the language items they dealt with during the LREs.

Another study that investigated the effects of task type on learner attention to form was [6]'s study involving fourteen university EFL learners in Spain. She analysed the learners' attention to form during two communicative tasks: dictogloss and text reconstruction. The learners' interaction was transcribed and LREs were identified, tabulated and coded. Results of the study showed that learners' attention to form was task-dependent with eight times more LREs elicited during the textreconstruction task compared to the dictogloss task. The author argued that perhaps the dictogloss was not so successful in eliciting LREs because learners were more focused on writing a coherent paragraph, than engaging in discussions about language choices.

[1] investigated the amount and nature of LREs that occur when learners worked collaboratively on meaningful output activities and mechanical output activities. He also investigated whether the focus of the LREs were in grammatical or meaning-based features of the language. His participants were thirtysix Farsi learners within the ages of 12 to 18 in two intact classes of an intensive English program. He found that the meaningful output activity elicited significantly more LREs than the mechanical output activities. Also, most of the LREs in the mechanical activities focused on grammatical forms, while almost half of the LREs in the meaningful activities focused on meaning and lexis. The results indicate that types of task can have differential effects on the amount and nature of LREs that occur. Most of the LREs were also resolved correctly in both groups which would indicate that collaborative tasks could 
have beneficial effects on learner output and resolution of errors.

Studies on LREs, as exemplified by the reviewed studies, consistently indicate that LREs could have positive effects on L2 learning. The following section hones in on task complexity variables and their effects on L2 learning.

\section{Task complexity and L2 learning}

A number of studies has manipulated task complexity variables along the resource-directing dimension with different task conditions to investigate their effects on L2 learning. A recent study by [28] investigated levels of complexity, accuracy and time on task when participants performed a task orally and in written form. The participants were seventy-eight Spanish and Catalan ESL students in two universities in Barcelona. They were divided into two groups: an oral group and a writing group. All the participants in both groups engaged in the simple and complex versions of a task (the Fire Chief Task) that were counterbalanced. The oral data were collected from the participants individually, while the written data were collected in one group session. Data transcribed from the oral performance and the written essays were analysed for linguistic complexity (mean length of AS units), propositional complexity, accuracy (total number of errors per 100 words) and time on task. Repeated measures MANOVA was run and results showed that there were significantly higher syntactical and lexical complexity levels produced in the written task compared to the oral task. Results also showed that the complex version of the task produced more sophisticated words, ideas and extended ideas, as opposed to the simple version of the task. Propositional complexity measures found more idea units in the oral data. However, there was a higher ratio of extended ideas in the written essays. There were no significant differences in the accuracy measure for the oral and written tasks in both the complex and simple versions of the task. Finally, the time-on-task scores were higher for the written task, which means more time was spent on the written task than the oral task. The researchers concluded that task modality has differential effects on task performance. Also, the different inherent characteristics of the two modes of language production would contribute to L2 learning in unique and complementary ways and teachers and learners should capitalise on these for a balanced approach in language learning. The study also supported the Cognition Hypothesis which stipulates that more complex tasks would produce greater complexity levels.

[20] also manipulated task complexity along the resource-directing dimension by manipulating the here-and-now variable along with two resource- dispersing variables which were planning time and single task. The participants were sixty-five Iranian ESL learners. The participants were randomly assigned into four groups, which each group performing a story-retelling task at different levels of cognitive demand in terms of the here-and-now, planning time and single task variables. The participants' oral production was audio-taped, transcribed and coded to measure structural complexity, accuracy, fluency and lexical complexity. MANOVA results indicated that simultaneously manipulating different variables in relation to cognitive demands of narrative tasks would result in differential effects on structural complexity, accuracy, fluency and lexical complexity. The results of the study supported Robinson's Cognition Hypothesis which contends that keeping tasks simple along the resourcedispersing dimension, while making them more demanding in the resource-directing dimension (here-and-now) would result in increases in complexity and accuracy levels. The authors also concluded that cognitive demands of tasks could be a key consideration for course developers in terms of choice, design and sequencing of L2 tasks.

[16] investigated the effects of using two simple versions and two complex versions of an argumentative task on focus on form-meaning connections. The study investigated the effects of task complexity on linguistic output and the frequency and type of learning opportunities that arise as a result of interaction. The participants were forty-three ESL learners in 6 intact classes. Sequence of tasks was counterbalanced to reduce task sequence effects. All classroom interactions were audiorecorded and transcribed. They were then analysed using speech production measures for linguistic complexity and accuracy, and lexical diversity. Interactional measures such as clarification requests, confirmation checks, recasts and metalinguistic talk were also identified. The results indicated that when task complexity was increased, participants produced more lexically diverse and accurate language. Participants were also more likely to show advances in constructions in the more complex task compared to the less complex task. Thus, the researcher argued that enhanced task complexity does not afford less attentional resources to accuracy of language production. Therefore, the results appear to be more compatible with Robinson's Cognition Hypothesis compared to Skehan's Trade-Off hypothesis. Results for the interactional measures also showed support for Robinson's Cognition Hypothesis. There were significantly more Language-related Episodes (LREs) during the enhanced complexity task compared to the less complex tasks.

In a similar vein, [7] investigated the effects of manipulating intentional reasoning on fluency, complexity and accuracy. The study set out to test 
whether the complex intentional reasoning task would result in higher accuracy and complexity levels at the expense of fluency as predicted by Robinson's Cognition Hypothesis. The participants were twenty-four Japanese students who were either majoring in English or taking English for Academic purposes (EAP). Each participant underwent the experiment individually with the researcher. Each participant carried out three tasks- the simple reasoning task, complex reasoning task and no reasoning task, with the order of the tasks counterbalanced using a latin-square design. Fluency was measured using un-pruned and pruned speech rate, and disfluency measures. Complexity and accuracy were measured using S-nodes per T-unit, Guiraud 2000, and percentage of error-free T-units. Results of the fluency measure using pruned and unpruned speech rate measures went against Robinson's Cognition Hypothesis as the means for the three levels of reasoning tasks showed no significant difference. However, the disfluency measure showed a significant difference with the highest mean for disfluency recorded by the complex task, thus confirming the prediction of Robinson's Cognition Hypothesis. Results also supported Robinson's contention that the complex task would result in greater syntactic complexity as the S-nodes per T-unit measure showed a significant difference of means between the no reasoning task and complexity task with a higher mean score recorded by the complex reasoning task. Similarly, the means for the Guiraud 2000 measure showed that the complex reasoning task produced significantly enhanced lexical complexity as opposed to the no reasoning task which would support Robinson's Cognition Hypothesis. The accuracy measure also supported Robinson's claims, as the complex reasoning task and simple reasoning task produced significantly greater accuracy levels compared to the no complexity task. In short, the results largely support Robinson's Cognition Hypothesis, and manipulating task complexity levels would have differential effects on language performance.

\subsection{The Opinion gap task and Dictogloss}

Two consensus tasks were selected for the purpose of this study. The low complexity task was a revised version of the dictogloss task using argumentative texts, while the high complexity task was the opinion-gap task.

The opinion-gap task with only a topic given to the learners would require learners to understand and analyse the question given, access their prior knowledge of content and language forms, build a line of argument by expressing opinions, giving justifications and build on the knowledge though interaction. Students were assigned one out of two options, and the arguments must be based on the assigned option. This was to ensure that there were differences in opinion and argumentation took place. For example, one of the questions was 'Identify and explain the best way to reduce the problem of snatchthefts in our country (a) Carry out awareness campaigns (b) Increase enforcement efforts.' To answer this question based on the option he is assigned to, a learner would have to access his knowledge about the subject matter. This knowledge could come from his own experience, his observations, movies or television programmes he has watched, his readings, or other people's account of their experiences. Then, this learner would have sort out his thoughts and reason them out. While reasoning, he would have to think of justifications and cause-effect relationships. Then, in dyads, the learners would have to come to a consensus, and this would require them to discuss and argue out their thoughts. Again, this would require articulation of justifications and cause-effect relationships. Then, they will have to write a paragraph to answer the question given based on the consensus they have arrived at.

On the other hand, for the dictogloss task, the content for the topic will be read aloud for the learners. During the first reading, the learners just listen. Then, the text was read out again. During this time, learners can write down notes. They would then be required to reconstruct the text in dyads. Thus, in terms of reasoning demands, it is considered relatively less demanding compared to the opiniongap task. Learners would need to access their knowledge of the content that they heard about 5 minutes beforehand, and they have the short-notes that they scribbled down to help them in the reconstruction. Also, learners would have each other to help fill in gaps of the parts that they missed out on. Nonetheless, negotiations of form and meaning were expected to occur when they attempt to produce a syntactically accurate and textually cohesive paragraph during the text-reconstruction stage.

Using two task types at differing ends of the task complexity continuum, in terms of reasoning demand, is aimed at examining the different learning opportunities that occur, which would lead to L2 development, provided by tasks of different complexity levels. As mentioned previously, L2 development, in the context of the current research, would be measured by the amount of noticing that occurs as reflected by the frequency of LREs.

\section{The current study}

The current research investigated the main and interaction effects of reasoning demand (RD) and type of negotiation on frequency of LREs during dyadic interaction to determine how the frequency of LREs was affected by RD levels and the type of negotiation that learners used in their interaction. 
The study also sought to gauge the types of grammatical items that learners focused on during negotiation of form.

\section{Research questions}

This study sought to answer the following questions:

1. What are the main and interaction effects of $\mathrm{RD}$ and types of negotiation on the frequency of LREs?

2. What are the grammatical items learners focused on when they engage in tasks of high and low reasoning demand?

\section{Hypotheses}

Following the predictions of the Cognition Hypothesis (Robinson, 2001, 2003, 2005, 2007), the following research hypotheses were formulated:

1. Hypothesis 1: The +RD task will result in more LREs compared to the -RD task.

2. Hypothesis 2: The +RD task will result in more negotiation of meaning compared to the $-\mathrm{RD}$ task.

\section{Participants}

The participants were seventy-six 18-year old Malaysian ESL learners at Form 6 level (i.e., equivalent to pre-university level) in a secondary school in Malaysia. There were 32 male students and 44 female students. All the students were randomly assigned into one of four groups.

\section{Tasks}

The researchers developed and adapted the dictogloss and opinion-gap tasks for use in the four classes. The students were allowed to pick their own partners, but they had to maintain the same partners till the end of all the sessions. Each dyad engaged in both task types but in different orders. This would help reduce subject-characteristic and tasksequencing threats. Each task type was carried out three times in an interval of 1 to 3 days. Therefore, each student was engaged in 3 dictogloss tasks and 3 opinion gap tasks.

\section{Data collection}

Research Question 1: What are the main and interaction effects of RD and type of negotiation on the frequency of LREs? The recordings of discussions in dyads for the dictogloss and opiniongap activities were transcribed verbatim in order to identify the LREs for each pair. The LREs were identified and coded as either having negotiation of meaning or negotiation of form. The frequency of occurrence for each type of negotiation was tabulated. The results were analysed using descriptive statistics and repeated-measures ANOVA. The results would show the main and interaction effects of RD and type of negotiation on frequency of LREs. Effect size and power analysis levels were also reported.

Research Question 2: What are the grammatical items learners focused on when they engage in tasks of high and low reasoning demand? Using LREs identified in the audio recordings, the grammatical items focused on were identified. The categories of coding of grammatical items would range from oneword items (e.g., adverbs), to phrases (e.g., phrasal verb), sentence structures and linking ideas. The data gathered would shed light on the types of grammatical items the two different task-types could elicit and thus, assist educators in selecting suitable task types to elicit intended linguistic items, if a 'planned focus-on-form' was employed. Also, the results could potentially help determine learners' stage of 'developmental readiness' [14][15] as reflected by the grammatical items learners focus on during LREs. This is because the grammatical focus in LREs could be an indication to educators that the learners are ready to address these grammar items through pedagogical intervention. The data were analysed using descriptive statistics.

\section{Results}

Research question 1 addresses the main effects of reasoning demand and types of negotiation and their interaction effects on frequency of LREs. The interaction was transcribed and types of negotiation were identified. Table 1 shows the descriptive statistics of the negotiation of meaning and negotiation of form that occurred during the two levels of reasoning demand.

Table 1. Descriptive statistics: LREs involving negotiation of meaning and negotiation of form

\begin{tabular}{llcc}
\hline RD & Type of negotiation & Mean & SD \\
\hline$+\mathrm{RD}$ & Negotiation of meaning & 12.64 & 4.97 \\
\cline { 2 - 4 } $\mathrm{N}=76$ & Negotiation of form & 1.25 & 1.80 \\
\hline -RD & Negotiation of meaning & 7.37 & 3.17 \\
\cline { 2 - 4 } $\mathrm{N}=76$ & Negotiation of form & 5.57 & 4.01 \\
\hline $\mathrm{RD}=$ Task Reasoning Demand & & \\
& & &
\end{tabular}

There was a total of 2049 LREs with 1521 involving negotiation of meaning and 528 involving negotiation of form across the four groups during $+\mathrm{RD}$ and $-\mathrm{RD}$ in dyadic TC. This would mean that in the 6 lessons that involved dyadic TC (with 3 lessons in $+\mathrm{RD}$ and 3 lessons in -RD), the average number of LREs that each learner produced was 27 (2049 LREs $\div 76$ learners). This would also mean that 
a learner produced, on average, 4 LREs per lesson (27 LREs $\div 6$ sessions).

The highest mean was recorded in the number of LREs with negotiation of meaning that occurred during + RD ( $M=12.64)$, while the lowest mean was recorded in the number of LREs with negotiation of form that occurred during $+\mathrm{RD}(\mathrm{M}=1.25)$. Table 2 shows the main and interaction effects RD and type of negotiation had on the number of LREs that occurred.

Table 2. Repeated-measures ANOVA: The effects of RD and type of negotiation on frequency of LREs

\begin{tabular}{lccccc}
\hline Source & df & F & $\boldsymbol{p}$ & $\begin{array}{c}\text { Partial } \\
\text { eta }^{2}\end{array}$ & $\begin{array}{c}\text { Observed } \\
\text { power }\end{array}$ \\
\hline Within & & & & & \\
subjects & & & & & \\
RD & 1 & 1.37 & .25 & .02 & .21 \\
Neg. & 1 & 302.89 & .00 & .80 & 1.00 \\
RD*Neg. & 1 & 165.16 & .00 & .69 & 1.00 \\
\hline
\end{tabular}

$\mathrm{RD}=$ Task Reasoning Demand, Neg.= Negotiation

The table indicates that the RD level did not have a significant effect on the number of LREs that occurred. On the other hand, the type of negotiation (meaning vs. form) had a significant effect on the number of LREs that occurred. More specifically, negotiations of meaning resulted in significantly higher means in both high and low RD. Similarly, the interaction between RD and type of negotiation had a significant effect on the number of LREs that occurred. This interaction is illustrated by figure 1 .

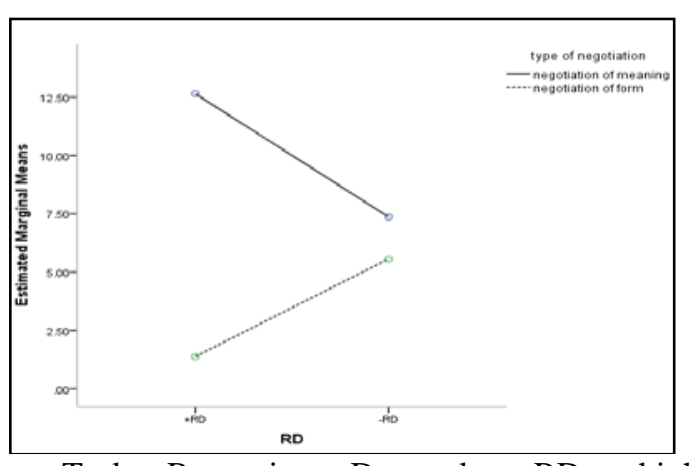

$\mathrm{RD}=$ Task Reasoning Demand, $+\mathrm{RD}=$ high reasoning demand task, $-\mathrm{RD}=$ low reasoning demand task

Figure 1. Interaction effect between reasoning demand and type of negotiation on LREs

Figure 1 shows the estimated marginal means of LREs as a result of the interaction between reasoning demand and type of negotiation. The contrast is significant $(F=165.16, p=.00)$. This means that the distance between the mean of LREs during negotiation of meaning and the mean of LREs during negotiation of form in a $+\mathrm{RD}$ context is significantly larger than the distance between the mean of LREs during negotiation of meaning and the mean of LRES for negotiation of form in a -RD context. We could conclude that the number of LREs for negotiation of meaning, as opposed to negotiation of form is significantly greater in a $+R D$ context than in $\mathrm{a}-\mathrm{RD}$ context. Conversely, the number of LREs for negotiation of form, as opposed to negotiation of meaning is significantly lower in a $+\mathrm{RD}$ context than in a $-\mathrm{RD}$ context.

\section{Discussion}

The results are discussed in relation to the hypotheses presented earlier.

Hypothesis 1: The $+\mathrm{RD}$ task will result in more LREs compared to the -RD task.

This hypothesis was tested by analysing the frequency of LREs that occurred during the +RD task and the -RD task. [17], [18], [19] predicted that tasks with relatively higher cognitive demand will produce a higher number of LREs than less demanding tasks. Previous research also provides empirical support for this prediction. For example, [9] in a study involving 34 Korean ESL learners, used two tasks, with high (++complex, +complex) and low (simple) RD versions for each task. Results showed that the learners engaged in the ++ complex and +complex tasks produced significantly more LREs that learners engaged in the simple task.

In line with Robinson's Cognition Hypothesis, the current study predicts that learners would engage in more LREs when performing the +RD task, as opposed to the -RD task. However, the current study does not seem to support this hypothesis with only a slightly higher mean total of 13.89 LREs produced during the $+\mathrm{RD}$ task compared to the mean total of 12.94 LREs produced during the $-\mathrm{RD}$ task. The repeated-measures ANOVA also found the result to be insignificant $(\mathrm{p}=.25)$.

Interestingly, most of the LREs produced during $+\mathrm{RD}$ involved negotiation of meaning $(\mathrm{M}=12.64)$ as opposed to negotiation of form $(\mathrm{M}=1.25)$. This result was found to be significant $(p=.00)$. The significantly higher focus on meaning rather than form during +RD could be explained by Skehan's Trade-off Hypothesis. With no content support in the form of a text (unlike the -RD task), learners' attention was diverted from dealing with language forms to coming up with the content for the task. [21] also argues that high task demands may have processing implications, in terms of overloading the limited capacity system in such a way that noticing becomes less likely.

Meanwhile the results for the interaction between task reasoning demand and type of negotiation indicated that the number of LREs during negotiation of meaning, as opposed to negotiation of form is significantly greater in a $+\mathrm{RD}$ context than in a $-\mathrm{RD}$ 
context. Conversely, the number of LREs during negotiation of form, as opposed to negotiation of meaning is significantly lower in a $+\mathrm{RD}$ context than in $\mathrm{a}-\mathrm{RD}$ context.

In sum, though there was no significant difference between the number of LREs produced during the $+\mathrm{RD}$ and $-\mathrm{RD}$ tasks, the +RD task resulted in significantly more LREs with negotiation of meaning as opposed to negotiation of form. Therefore, Robinson's claim that cognitively complex tasks (+RD in the current study) would lead to more interaction and modified output was actually partly supported. The results also indicated that -RD resulted in significantly more negotiation of form as opposed to negotiation of meaning. The significantly higher number of negotiations of form during -RD could be explained by Skehan's Trade-off Hypothesis which suggests that decreasing task demands (-RD in the current study) would free attention from procedural demands, thus allowing more attention to language use. This resulted in more LREs with negotiation of form while learners were engaged in the dictogloss task (-RD) as opposed to the opinion-gap task (+RD). The provision of substantial input for the learners in the dictogloss task made it less demanding than the opinion-gap task which did not provide any form of textual support for the learners.

Hypothesis 2: The +RD task will result in more negotiation of meaning compared to the $-\mathrm{RD}$ task.

[17][18][19] posit that complex tasks will increase the cognitive demands of the tasks and consequently produce a higher amount of negotiation of meaning than simple tasks. He theorises that more complex versions of tasks can lead to more learning opportunities, hence more LREs compared to simpler versions of tasks. In one of his studies that investigated the Cognition Hypothesis, [19] used three interactive tasks at three levels of complexity making resource-directing demands on L2 oral task performance. The participants were 42 Japanese ESL university students. Learner-learner interaction was recorded and analysed. The results showed that the more complex tasks resulted in more turns, and greater number of clarification requests and confirmation checks. In line with Robinson's theory, the current study predicts that learners would engage in more negotiation of meaning as shown by a higher occurrence of LREs in this type of negotiation when performing $+\mathrm{RD}$, as opposed to the $-\mathrm{RD}$ task.

This hypothesis was proven to be true with a mean total of 12.64 LREs involving negotiation of meaning during $+\mathrm{RD}$ as opposed to a mean total of 7.37 LREs involving negotiation of meaning during $-\mathrm{RD}$. This difference was found to be significant $(\mathrm{p}=$ .00 ). This would mean that there were more attempts at bridging the gap in communication during $+\mathrm{RD}$ than the -RD task.
The interaction data with negotiations of form were also coded for their grammatical focus. Data with negotiation of meaning, focus on vocabulary, pronunciation, spelling or punctuation were not included in this analysis. Table 3 shows the number of LREs and grammatical features each task generated.

Table 3. Grammatical features focused on during negotiation of form

\begin{tabular}{lcccc}
\hline & \multicolumn{2}{c}{ Dictogloss } & \multicolumn{2}{c}{ Opinion-gap } \\
\cline { 2 - 5 } & $\mathrm{N}$ & $\begin{array}{c}\text { Per } \\
\text { cent }\end{array}$ & $\mathrm{N}$ & $\begin{array}{c}\text { Per } \\
\text { cent }\end{array}$ \\
\hline $\begin{array}{l}\text { Grammatical } \\
\text { features }\end{array}$ & & & & \\
\hline Verb tense/aspect & 56 & 13.24 & 13 & 12.38 \\
\hline Prepositions & 31 & 7.33 & 8 & 7.62 \\
\hline Conjunctions & 21 & 4.96 & 6 & 5.71 \\
\hline Determiners & 27 & 6.38 & 10 & 9.52 \\
\hline Sentence structure & 42 & 9.93 & 15 & 14.29 \\
\hline S-V agreement & 75 & 17.73 & 16 & 15.24 \\
\hline Phrasal verbs & 37 & 8.75 & 12 & 11.43 \\
\hline Linking ideas & 32 & 7.57 & 8 & 7.62 \\
\hline Passive & 26 & 6.15 & 6 & 5.71 \\
\hline Adjectives & 24 & 5.67 & 2 & 1.90 \\
\hline Adverbs & 18 & 4.26 & 5 & 4.76 \\
\hline Pronouns & 24 & 5.67 & 2 & 1.90 \\
\hline Affixes & 10 & 2.36 & 2 & 1.90 \\
\hline Total LREs & 423 & \multicolumn{3}{c}{105} \\
\hline
\end{tabular}

Table 3 shows a striking difference in the number of LREs generated by the two tasks. Specifically, the results show that the dictogloss task generated four times more LREs than the opinion-gap task. Perhaps, as argued by the Trade-off Hypothesis [23], the input in the form of content the learners received in the dictogloss task allowed learners to focus more on forms used, whereas, the absence of any help in the form of content for the written output made learners more focused on negotiating meaning rather than form during the opinion-gap task. Of course, a substantially greater number of LREs does not indicate higher success in learning though it does imply that certain task-types could elicit greater opportunities for repair of grammatical forms.

The table also shows that the highest percentage of LREs was recorded by subject-verb agreement at $17.73 \%$ for the dictogloss task and $15.24 \%$ for the opinion-gap task. The second highest percentage was for verb tense/aspect (13.24\%) for the dictogloss task and sentence structure (14.29\%) for the opinion-gap task. Meanwhile, the third highest was for sentence structure $(9.93 \%)$ for the dictogloss task and verb tense/aspect (12.38\%) for the opinion-gap task. This was followed by phrasal verbs for both the dictogloss (8.75\%) and the opinion-gap (11.43\%) tasks. It is interesting to note that though the levels of reasoning demand differ, the grammatical features that received the most attention were somewhat similar. 


\section{Theoretical implications}

This section discusses the implications the findings of the current research have on some of these Hypotheses. In particular, this section discusses how the findings in the current study corroborate, contradict or expand on some of the contentions put forth by Robinson's Cognition Hypothesis [19] and Skehan's Trade-off Hypothesis [23].

The findings showed some support for Robinson's Cognition Hypothesis [19] with regards to the amount of negotiation that could occur during the $+\mathrm{RD}$ and $-\mathrm{RD}$ tasks. Though the results showed a non-significant mean difference in the number of LREs that occurred during the $+\mathrm{RD}$ and $-\mathrm{RD}$ tasks, there was a significant difference between the LREs that focused on meaning in the $+\mathrm{RD}$ and $-\mathrm{RD}$ tasks. This would imply that though negotiation of meaning results in significantly higher frequency of LREs, the same cannot be said about negotiation of grammatical forms. In fact, inferential statistics showed that -RD resulted in a significantly higher mean of LREs that focused on grammatical forms as opposed to $+\mathrm{RD}$. This result appears to consolidate arguments made by Skehan in his Limited Attentional Capacity Model and the Trade-off Hypothesis. Skehan ([22], p.97) stresses that 'more demanding tasks consume more attentional resources simply for task transaction, with the result that less attention is available for focus on form'. By implication, tasks that are less complex, in terms of reasoning demand, would generate greater attention to grammatical forms, as opposed to more complex tasks.

The descriptive part of the study also yielded some interesting findings with theoretical implications on Pienemann's Processibility Theory [14], [15] which is part of the Multidimensional Model. Even though Pienemann's Processibility Theory [14] was not discussed in review of literature, as it was not directly relevant in explaining task complexity models and learner-learner interaction, it could be relevant in explaining some of the findings in this study. Peinemann [14] in his Processibility Theory posits that developmental features and natural orders are related to learners' gradually expanding processing space and the freeing of attentional capacity (Robinson, 2001b, p.34). Therefore, target features need to be aspects of language that learners are developmentally ready for pedagogical intervention. In the case of this study, despite the differences in task formats, the learners were seen to focus mostly on similar grammatical structures such as verb tenses and subject-verb agreement. Taking the Processibility Theory into consideration, it could be argued that the learners' focus on similar linguistic problems across task types could indicate that they are developmentally ready to address these problems through pedagogical intervention.

In sum, results from the current research provide some support for the arguments made in Robinson's Cognition Hypothesis and Skehan's Trade-off Hypothesis. It also hints at the useful application of Pienemann's Processibility Theory in explaining learner focus on certain grammatical forms during LREs.

\section{Pedagogical implications}

The current research shows that certain grammatical features were problematic for learners across both tasks. This could be an indication of learner readiness. Teachers could use this information to gear lessons towards addressing these problematic grammatical features. [25] for instance, suggested drawing learners' attention to form by making certain language features more salient in the input. [13], in a study involving 81 pre-university learners used reformulation and enhancement techniques to draw learners' attention to intended grammatical forms. The reformulation technique involves restructuring or recasting the learners' erroneous output, while the enhancement technique involves the use of input or feedback that makes the targeted item salient, for instance, by using a different font size or bolding the targeted items in the written input or output (based on the learners' errors). The authors found that using reformulation and enhancement techniques were useful in encouraging learners to notice errors.

The current research also points to the importance of using tasks to promote L2 learning. [4] opines that elements in a task would induce learners to use certain language forms and engage in cognitive processes such as analyzing and problemsolving that could contribute to L2 acquisition. As learners encounter problems in completing a task, they might also be pushed to deal with linguistic problems that hinder the completion of the task. Some researchers such as [10] and [27] found that collaborative tasks that require learners to produce written output could also draw learners' attention to accurate use of grammatical forms. These researchers argue that tasks which require collaboration among learners would be of particular benefit in developing learners' ability to use grammatical items accurately because the interaction and cooperation required by the tasks would elicit LREs related to language choices. Such reflections and verbalisation would serve as negotiations of form which would raise learners' attention to gaps in their interlanguage, which the learners' will try to fill through the use of interactional feedback and modified output. This would then promote learning.

Another important implication of using tasks in the classroom is that teachers need to understand the 
differential effects that tasks have on L2 learning. Thus, tasks need to be designed and selected according to, among others, learners' needs, proficiency levels, and the kind of interaction the teacher wants to encourage. Getting students to verbalise language in dyads or groups is crucial because as [10] pointed out, it is difficult for teachers to interpret the effects of input on learners. Thus, when learners interact with their peers as a reaction to the input, both learners and the teacher can get more meaningful information about the learners' current interlanguage level. Common errors among learners could be target language items that the teacher might want to address through the use of tasks with pre-targeted language items. These tasks might include dictogloss tasks with texts that are loaded with the target language items.

The current study shows that consensus tasks such as the dictogloss task could encourage noticing and interaction, which are important conditions for L2 learning. Furthermore, the task encourages learners to reflect on their own output and pay close attention to language use. The dictogloss in the current study did not have pre-targeted language items, and learners focused on form as and when they deemed necessary. However, other researchers have used the dictogloss task with pre-targeted language items. For example, [11] in a study on the effect of interaction in acquiring L2 grammar have used the dictogloss task to target on passive forms. Thus, in the text read to the learners, the particular grammar construction, 'occurs frequently and stands out saliently in the input' ([11], p. 334). In the context of classroom teaching, in order to pre-target grammatical items, the teacher must first identify the learners' processing capability and readiness to concentrate on the particular linguistic forms. This would be in line with Pienemann's Teachability Hypothesis, which is a subset of the Processability Theory [14], [15]. The Teachability Hypothesis predicts that (a) stages of acquisition cannot be skipped through formal instruction, and (b) instruction will be beneficial if it focuses on structures from the next stage. Thus, before pretargeting linguistic items teachers would need to do a needs assessment perhaps through the use of a variety of testing methods. [3], for example, carried out an interlanguage analysis in the classroom to identify the linguistic problems learners had.

Thus, teachers have a crucial role of critically evaluating tasks for, among others, their level of cognitive demands on learners, the amount of negotiation they could potentially induce, and the linguistic items learners would focus on based on the saliency of the intended grammatical items in the input and learner readiness.

\section{References}

[1] Abadikhah, S., (2011). "Investigating Language-related Episodes during Mechanical and Meaningful Output Activities”, International Journal of English Linguistics. 1(2), 281-294.

[2] Adams, R., (2007). Do Second Language Learners Benefit from Interacting with Each Other? In A. Mackey (Ed.), Conversational Interaction in Second Language Acquisition: A Series of Empirical Studies (pp. 29-51), Oxford: Oxford University Press.

[3] Doughty, C., Varela, E., (1998). Communicative Focus on Form. In C. Doughty and J. Williams (Eds.), Focus on Form in Classroom Second Language Acquisition (pp. 114-138). Cambridge: Cambridge University Press.

[4] Ellis, R., (2000). "Task-based Research and Language Pedagogy”, Language Teaching Research. 4 (3), 193-220.

[5] Foster, P., (1998). "A Classroom Perspective on the Negotiation of Meaning”, Applied Linguistics, 19(1), 1-23.

[6] Garcia-Mayo, M., (2002). "The Effectiveness of Two Form-focused Tasks in Advanced EFL

[7] Ishikawa, T., (2008). "The Effect of Task Demands of Intentional Reasoning on L2 Speech Performance", The Journal of Asia Tefl, 5(1), 29-63.

[8] Jackson, D., (2001). "Language-related Episodes.”, ELT Journal, 55(3), 298-299.

[9] Kim, Y.J., (2009). “The Effects of Task Complexity on Learner-learner Interaction”, System, 37(2), 254-268.

[10] Kowal, M., Swain, M., (1994). "Using Collaborative Language Production Tasks to Promote Students' Language Awareness”, Language Awareness, 3(2), 73-93.

[11] Kuiken, F., Vedder, I., (2002). "The Effect of Interaction in Acquiring the Grammar of a Second Language”, International Journal of Educational Research, 37, 343-358.

[12] Long, M., (1983). Native speaker/non-native Speaker Conversation in the Second Language Classroom. In $\mathrm{M}$. Clarke and J.Handscombe (Eds.). On TESOL '82: Pacific Perspectives on Language and Teaching (pp. 94-120), Washington DC: TESOL.

[13] Mohammad Lotfie, M., Abd Samad, A., (2007). "Noticing and Grammatical Accuracy in ESL learners' Writing”, Indonesian Journal of English Language Teaching, 3(2), 202-215.

[14] Pienemann, M., (1988). "Is language Teachable? Psycholinguistic Experiments and Hypotheses”, Applied Linguistics, 10(1), 52-79.

[15] Pienemann, M., (2012). Processability Theory and Teachability. The Encyclopedia of Applied Linguistics, Malden, MA: Blackwell Publishing. 
[16] Révész, A., (2011). “Task complexity, Focus on L2 Constructions, and Individual Differences: A Classroombased Study”, Modern Language Journal, 95, 162-181.

[17] Robinson, P., (2001). Task Complexity, Cognitive Resources, and Syllabus Design: A Triadic Framework for Investigating Task Influences on SLA. In P. Robinson (Ed.), Cognition and Second Language Instruction (pp. 287-318), Cambridge: Cambridge University Press.

[18] Robinson, P., (2003). Attention and Memory in SLA. In C. Doughty and M. H. Long (Eds.), Handbook of Second Language Acquisition (pp. 631-78), Oxford: Blackwell.

[19] Robinson, P., (2007). "Task Complexity, Theory of Mind, and Intentional Reasoning: Effects on L2 Speech Production, Interaction, Uptake and Perceptions of Task Difficulty”, IRAL, 45, 193-213.

[20] Saeedi, M., Ketabi, A., Kazerooni, A.R., (2012), “The Impact of Manipulating Task Complexity on EFL Learners' Performance”, GEMA Online ${ }^{\circledR}$ Journal of Language Studies, 12(4). 1057-1075.

[21] Schmidt, R., (1990). "The Role of Consciousness in Second Language Learning”, Applied Linguistics, 11(2), 17-46.

[22] Skehan, P., (1998). A Cognitive Approach to Language Learning, Oxford: Oxford University Press.

[23] Skehan, P., (2009). "Modelling Second Language performance: Integrating complexity, accuracy, fluency, and lexis”, Applied Linguistics, 30(4), 510-532.

[24] Skehan., P. Foster, P., (2001). Cognition and Tasks. In P. Robinson (Ed.). Cognition and Second Language Instruction (pp. 183-205), Cambridge: Cambridge University Press.

[25] Spada, N., Lightbown, P., (1993). "Instruction and the Development of Questions in L2 Classrooms", Studies in Second Language Acquisition, 15, 205-224.

[26] Storch, N., (2008). "Metatalk in a pair work activity: Level of Engagement and Implications for Language Development”, Language Awareness, 17(2), 95-114.

[27] Swain, M. S. Lapkin, S., (1998). "Interaction and Second Language Learning: Two Adolescent French Immersion Students Working Together", Modern Language Journal, 82, 320-337.

[28] Vasylets, O., Gilabert, R., Manchon, R.M., (2017). "The Effects of Mode and Task Complexity on Second Language Production”, Language Learning, 67(2), 394430. 